\title{
A MODEL FOR SOIL OXYGEN DELIVERY TO WASTEWATER INFILTRATION SURFACES
}

\author{
J. Erickson, E. J. Tyler*
}

\begin{abstract}
Soil could accept onsite wastewater at rates two to three orders of magnitude higher than the current design loading rates if a clogging mat at the wastewater infiltration surface was limited or not present. The clogging mat controls system design, loading rate and life. Maintaining aerobic conditions at the wastewater infiltration surface could substantially reduce or eliminate clogging. This project is studying soil oxygen supply to the zone of clogging in soil. A model based on a form of Fick's Law for diffusive transport is being applied to oxygen diffusion to the wastewater infiltration surface. Gas filled porosity controlled by soil characteristics of texture, structure, consistence and water content as well as the distance to the supply of oxygen and rate of oxygen consumption control the flux, F, of oxygen. If the oxygen consumption rate exceeds the maximum flux of soil oxygen then the soil infiltration surface will become anaerobic. To maximize delivery of oxygen, soil components should be shallow, narrow and have separated infiltration areas. Using models that incorporate system depth, geometry, and oxygen diffusion coefficients in soil, efficient loading rates can be estimated. Design of wastewater infiltration surfaces should be based on both oxygen transport and hydraulics. In many cases, oxygen transport will be limiting and therefore the basis for design.
\end{abstract}

KEYWORDS. Absorption field, Biochemical oxygen demand, Biofilms, Flux, Onsite wastewater bed, Wastewater Absorption, Wastewater infiltration, Wastewater loading.

*Work of Small Scale Waste Management Project and Dept. of Soil Science, University of Wisconsin-Madison, 1525 Observatory Drive, Madison, WI, 53706; 608-265-2595; www.wisc.edu/sswmp.

In: K. Mancel (ed.) On-site wastewater treatment. Proc. of the $9^{\text {th }}$ International Symposium on Individual and Small Community Sewage Systems. ASAE. St. Joseph, MI. P.11-17.

Jenny Erickson is Research Assistant, Dept. of Soil Science and Small Scale Waste Manage-ment Project, University of Wisconsin-Madison.

E. Jerry Tyler is Professor of Soil Science and Director of the Small Scale Waste Management Project, University of Wisconsin-Madison, 1525 Observatory Drive, Madison, WI 53706; ejtyler@ facstaff.wisc.edu. 


\section{INTRODUCTION}

An efficient onsite wastewater system has a balance between the amount of oxygen entering the system with the amount of oxygen needed to decompose the organic matter and meet the demand for other reactions. If the amount of oxygen entering the system cannot meet the demand, a clogging mat will form. Clogging mats form between the gravel and the soil at the infiltration surface. If the system design can be manipulated to supply oxygen into the soil exceeding the rate needed, the life and loading rate of the onsite wastewater system can be greatly increased.

Aerobic bacteria use oxygen as their terminal electron acceptor to convert organic molecules to carbon dioxide and ammonia to nitrate. Oxygen is the most effective oxidizing agent; therefore decomposition in an aerobic setting is far more efficient than in an anaerobic environment. If the oxygen supply runs out, the bacteria are forced to use alternative means that are less efficient in order to decompose the wastewater. Under large bed onsite wastewater infiltration systems, the environment is likely anaerobic and methane accumulation may occur under the center of the infiltration surface. In this anaerobic environment, methane could be used as a reducing agent, but decomposition with methane is much less efficient than with oxygen. In this situation decomposition of the wastewater is much slower.

The total oxygen demand is measured by multiplying the biochemical oxygen demand (BOD) by the organic matter loading rate. The BOD is the amount of oxygen needed by the aerobic bacteria to decompose organic matter from a volume of the wastewater and supply other reactions. The wastewater loading rate is the volume of wastewater released into the soil in a unit of time. The mass flux is the amount of oxygen per unit area moving into the soil in a unit of time. Oxygen is supplied to the infiltration surface by diffusion in the soil atmosphere, and it can be calculated using a form of Fick's law (Yanful, 1993).

\section{DESCRIPTION OF MODELS}

In order to understand the ramifications of Fick's Law, two applications will be studied. In each example, the goal is to estimate the movement of oxygen from the ground surface to the infiltrative surface. The amount of oxygen dissolved in soil water is low and the movement of the oxygen in the water is slow. Therefore, most oxygen supplied to wastewater infiltration systems will be as a gas. Since the pressure of the soil atmosphere is nearly uniform in the soil, mass flow contributes very little to oxygen movement. Diffusion of oxygen is the major mechanism of transport. Soil factors affecting oxygen diffusion in the gaseous phase will control the supply of oxygen to infiltrative surfaces.

\section{$\underline{\text { Theoretical Background }}$}

The transport of oxygen from the atmosphere through the soil and eventually to the onsite system is by molecular diffusion. Diffusion is a response to the concentration gradient formed between the oxygen rich atmosphere and the oxygen poor wastewater infiltration site. 
The mass flux can be calculated using a form of Fick's first law of diffusion (Yanful, 1993) by:

$$
\mathrm{F}=-\theta_{\mathrm{a}} \mathrm{D}_{\mathrm{e}}\left(\frac{\Delta \mathrm{C}_{\mathrm{a}}}{\Delta \mathrm{h}}\right)
$$

where $\mathrm{F}$ is the mass flux of oxygen into the system $\left(\mathrm{mg} \mathrm{m}^{-2} \mathrm{sec}^{-1}\right), \mathrm{D}_{\mathrm{e}}$ is effective diffusion coefficient $\left(\mathrm{m}^{2} \mathrm{sec}^{-1}\right),\left(\Delta \mathrm{C}_{\mathrm{a}} / \Delta \mathrm{h}\right)$ is the change of oxygen concentration in the soil $\left(\mathrm{mg} \mathrm{m}^{-3}\right)$ as a function of depth $(\mathrm{m})$ and $\theta_{\mathrm{a}}$ is the air filled porosity $\left(\mathrm{m}^{3} \mathrm{~m}^{-3}\right) . \theta_{\mathrm{a}}$ is related to the degree of saturation of the soil (Yanful, 1993) by:

$$
\theta_{\mathrm{a}}=\theta_{\mathrm{t}}\left(1-\mathrm{S}_{\mathrm{r}}\right)
$$

where $\theta_{\mathrm{t}}$ is the total porosity and $\mathrm{S}_{\mathrm{r}}$ is the degree of saturation.

A typical soil might be comprised of $50 \%$ solid space and $50 \%$ void space. Both the individual soil particles and the organic material are considered solid space. The other half of the soil volume is filled with either liquid or gas. Porosity is the void space between the soil particles, and once these voids are connected they form pores or passages for the air or water to travel through.

The water content or degree of saturation $\left(\mathrm{S}_{\mathrm{r}}\right)$ of the soil greatly affects the oxygen flux $(\mathrm{F})$ through the system. As the degree of water saturation increases, the mass flux of oxygen decreases. Moisture in the soil is held with matric potential in the smaller pores, and the gases are transported through the larger pores in the system $\left(\theta_{\mathrm{a}}\right)$. As the moisture content increases, the next largest pores fill with water, which in turn traps or pushes the gas out of the soil and reduces the volume of pores for gas transport. As the water content increases, the gas filled pore space continuity decreases. Figure 1 depicts three degrees of saturation. In a typical wastewater infiltration system, the moisture content is high; therefore the gas filled volume is low. In this type of system much of the oxygen needed for the decomposition of the wastewater cannot reach the site of infiltration.

The mass flux of oxygen into the system is based on the oxygen diffusion coefficient $\left(\mathrm{D}_{\mathrm{e}}\right)$, which is a function of many parameters of the soil and the environment. One factor that influences the $D_{e}$ is the amount of large pores in the soil. As the amount of these large pores increase, the $D_{e}$ also increases. The volume and density of large pores in the soil is a reflection of the size and shape of the soil particles. However, generally as the particles size increases the total porosity decreases, and the number of large pores increases. Based on that reasoning, sand sized particles $(0.05-2 \mathrm{~mm})$ would have a greater $\mathrm{D}_{\mathrm{e}}$ than clay sized particles $(<2 \mu \mathrm{m})$, but clay would have a higher total porosity. The large void space between the sand particles allows the oxygen to diffuse through the soil much faster than through the clay-sized particles. At the same water potential the water content of clay is higher than sand. The shape of the individual grains also influences the oxygen diffusion coefficient. Irregular shapes do not form tight connections between the individual particles. The extra voids 
between the particles form pores that the oxygen can diffuse through easily. On the other hand, in compacted soils the pores have been compressed, therefore oxygen cannot be effectively transported. Occasionally the soil pores become twisted thus trapping the gas and water. The amount of these "twisted" pores is called tortuosity, and as the tortuosity increases the diffusion coefficient decreases.

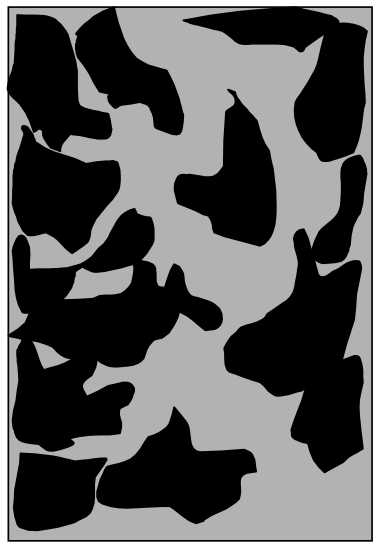

A

Soil particles

W ater filled pore space

A ir filled pore space

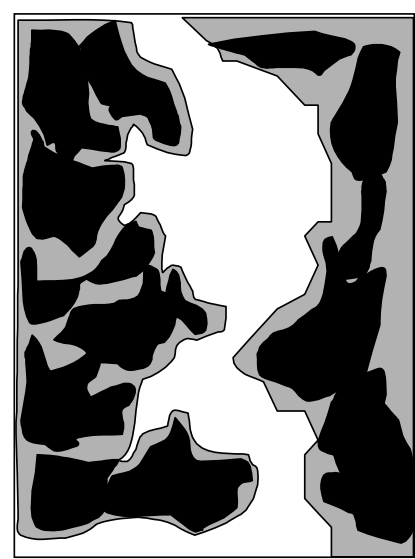

B

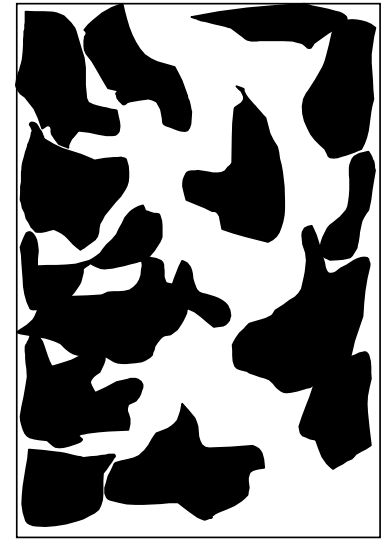

$\mathrm{C}$

Figure 1. Image A: A Soil Saturated with Water. Image B: Smaller Pores Filled with Water and Larger Pores Transport Gases Via Diffusion. Image C: A Completely Dry Soil.

The oxygen concentration gradient and the distance between the ground surface and the onsite wastewater infiltration site of the system affect the flux of oxygen into the system. A gradient is created when the oxygen concentration at the ground surface is equivalent to the atmospheric concentration $\left(\mathrm{C}_{\mathrm{a}}\right), 300,000 \mathrm{mg} \mathrm{L}^{-1}$, and assuming that the concentration $\left(\mathrm{C}_{0}\right)$ at the infiltration site is $0 \mathrm{mg} \mathrm{L}^{-1}$. This gradient is a function of the distance to the infiltration site. As the distance between the ground and the infiltration site of the system increases, the concentration gradient decreases. The greater the distance the infiltration bed is from the oxygen source the longer the path the oxygen must travel causing a decrease in the mass flux of oxygen. Since the gradient is the force behind diffusion, a steep concentration gradient is preferred.

\section{Model One}


For the simplest case, assume a large bed wastewater infiltration area that is both long and wide. Also, assume that the void volume in the aggregate of the bed is completely wastewater ponded. The problem is in determining the oxygen supply from the ground surface through the soil to the top surface of the bed, therefore this model accounts for only part of the entire system. Figure 2 is a cross-section of the system, revealing the ground surface at the top and the infiltration surface at the bottom. In this case, assume the oxygen flow paths are straight through the soil and parallel to each other as depicted by the parallel flow lines in fig 2 . This is known as laminar flow. Applying Fick's Law to this simple system, it is known that the oxygen flux is affected by the moisture content of the soil, the effective diffusion coefficient, and the change in concentration of oxygen with depth.

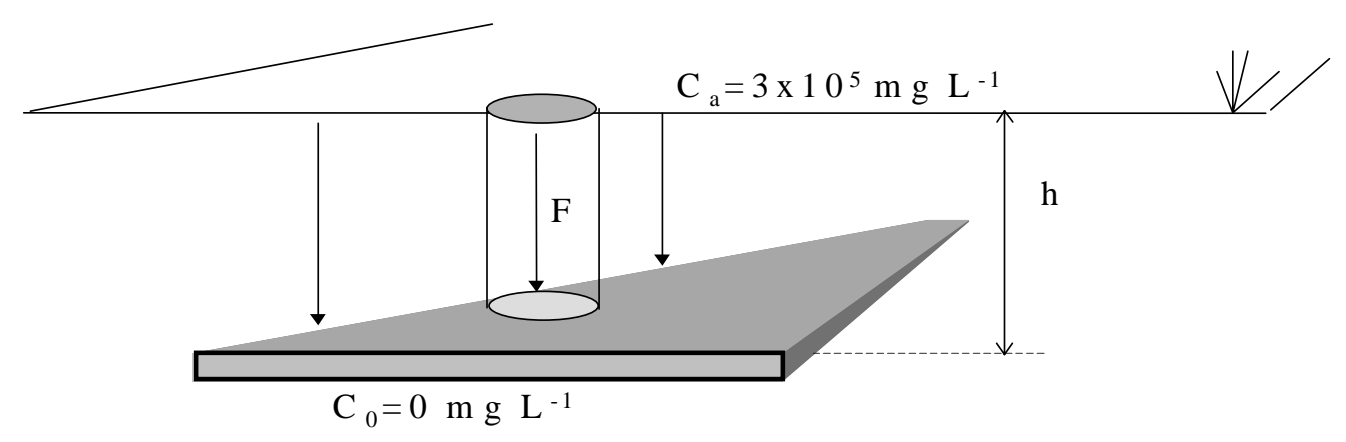

Figure 2. Schematic Representation of a Saturated Bed

$\left\{\mathrm{F}\right.$ is the laminar flux into the system, $\mathrm{C}_{\mathrm{a}}$ is the oxygen concentration in the atmosphere, and $\mathrm{h}$ is the depth of the system $\}$.

In order to test the model, Fick's Law of diffusion was applied to the simplified system in fig 2. The oxygen diffusion coefficient $\left(1.2 \mathrm{E}^{-8} \mathrm{~m}^{2} \mathrm{sec}^{-1}\right)$ accounted for the high moisture content found in most infiltration systems so the air filled porosity $\left(\theta_{\mathrm{a}}\right)$ was dropped from the equation (Jaynes and Rogowski, 1983). The atmospheric oxygen concentration, $3 \times 10^{5} \mathrm{mg} \mathrm{m}^{-3}$, was based on normal atmospheric conditions, and the depth of the system was $50 \mathrm{~cm}$. The system was loaded at $4 \mathrm{~L} \mathrm{day}^{-1} \mathrm{~m}^{-1}$, and the BOD was $150 \mathrm{mg} \mathrm{L}^{-1}$. The total oxygen demand was $0.0116 \mathrm{mg} \mathrm{m}^{-1} \mathrm{sec}^{-1}$, while the oxygen flux to the infiltration bed was $0.006 \mathrm{mg} \mathrm{m}^{-1} \mathrm{sec}^{-1}$. The demand for oxygen is much greater than the supply to the infiltrative surface; therefore a clogging mat will likely develop over time.

\section{$\underline{\text { Model Two }}$}

The same principles from the first model can be applied to the second model, a drip line distribution system. The oxygen diffusion coefficient, the concentration gradient, and the water content affect the system in a similar manner. In this system, a drip line is buried under 
the ground and, since the drip line is much longer than it is wide, it can be assumed to be twodimensional. The two-dimensional aspect of this model also assumes that oxygen diffuses to the drip line in a flow net pattern. A flow net pattern is one in which the gas diffuses through the soil from all sides of the drip tube. Figure 3 represents a theoretical pattern of oxygen diffusion to a drip line. For the second model, a new form of Fick's Law is utilized in order to account for the outer radius of the drip line and the flow net pattern of diffusion. This model is based on the assumption that the depth the drip line (h) is much greater than the radius (r) of the line.

$$
F=\frac{2 \pi D_{e} C_{a}}{\ln \left(\frac{h}{r}\right)}
$$

where $\mathrm{F}\left(\mathrm{mg} \mathrm{m}^{-1} \mathrm{sec}^{-1}\right)$ is the mass flux of the oxygen per unit length of drip line per unit time; $D_{e}$ is the oxygen diffusion coefficient $\left(\mathrm{m}^{2} \mathrm{sec}^{-1}\right)$ in the soil; $\mathrm{C}_{\mathrm{a}}\left(\mathrm{mg} \mathrm{m}^{-3}\right)$ is the concentration of oxygen in the atmosphere, $h(\mathrm{~m})$ is the depth and $\mathrm{r}(\mathrm{m})$ is the radius of the drip line (Carslaw and Jaeger, 1978).

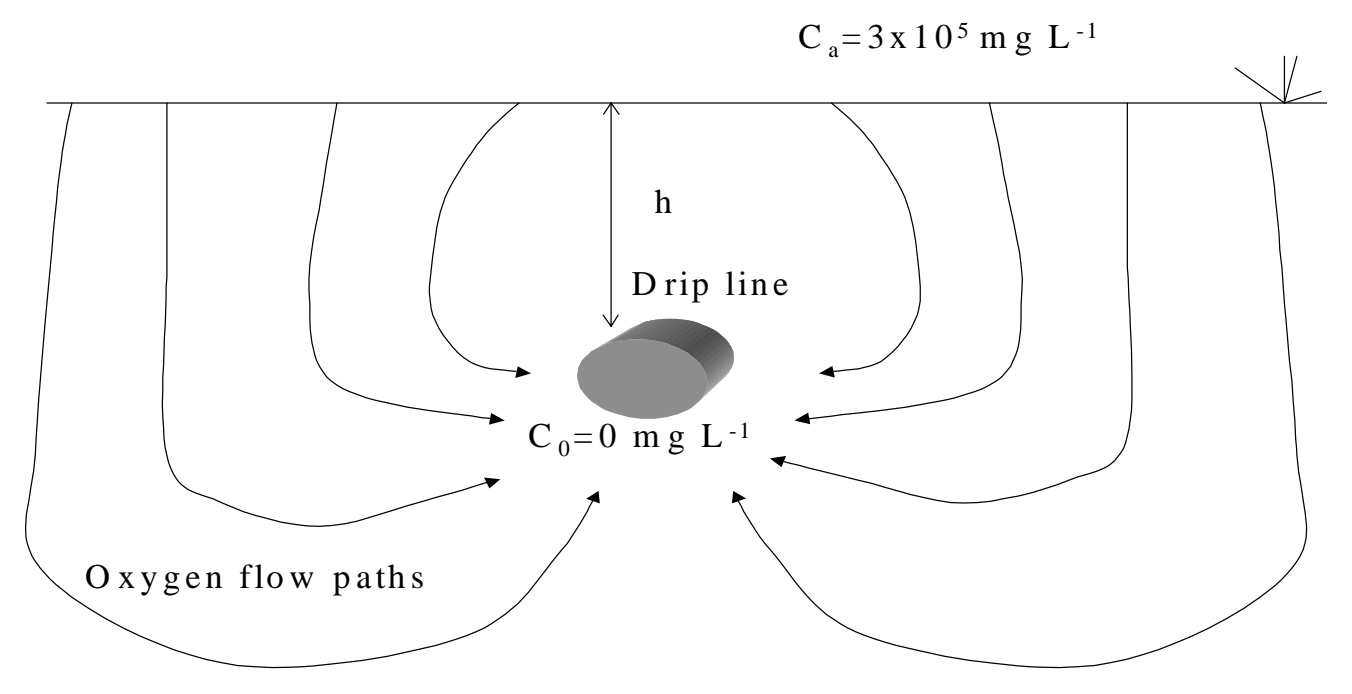

Figure 3. Schematic Representation of a Single Drip Line Emphasizing Flow Paths of Oxygen Diffusion $\left\{C_{a}\right.$ is the concentration of oxygen in the atmosphere and $\mathrm{h}$ is the depth of the drip line in the soil $\}$.

In order to test the second model, Fick's Law of diffusion was applied to a drip line and a trench. In both cases, the oxygen diffusion coefficient, $1.2 \mathrm{E}^{-8} \mathrm{~m}^{2} \mathrm{sec}^{-1}$, was assumed to be very low due to the high moisture content found in most infiltration systems (Jaynes and Rogowski, 1983). The atmospheric oxygen concentration, $3 \times 10^{5} \mathrm{mg} \mathrm{m}^{-3}$, was based on normal atmospheric conditions. In the first example, it was assumed that the drip tube had an outer diameter of $2.5 \mathrm{~cm}$, and it was buried $10 \mathrm{~cm}$ under the ground. This system was loaded 
at $3 \mathrm{~L} \mathrm{day}^{-1} \mathrm{~m}^{-1}$, and the BOD was $150 \mathrm{mg} \mathrm{L}^{-1}$. Applying Fick's Law to the model, the oxygen flux to the system was $0.0163 \mathrm{mg} \mathrm{m}^{-1} \mathrm{sec}^{-1}$, and the total oxygen demand was $0.0087 \mathrm{mg} \mathrm{m}^{-1}$ $\mathrm{sec}^{-1}$. The oxygen exceeds the demand therefore a clogging mat will not form under the drip line. Field experience verifies this conclusion.

The same equation was applied to a trench loaded with $15 \mathrm{~L} \mathrm{day}^{-1} \mathrm{~m}^{-1}$ and the BOD was 150 $\mathrm{mg} \mathrm{L}^{-1}$. Assume the trench was a cylinder, and it was buried $30 \mathrm{~cm}$ under the ground with a radius of $10 \mathrm{~cm}$ (fig. 4). The oxygen flux into the system was $0.021 \mathrm{mg} \mathrm{m}^{-1} \mathrm{sec}^{-1}$, while the total oxygen demand for this system is $0.043 \mathrm{mg} \mathrm{m}^{-1} \mathrm{sec}^{-1}$. In this case, the supply of oxygen into the system will not be enough to meet the demand; therefore a clogging mat will likely form under the trench. Field experience verifies this conclusion. Based on the conditions stipulated, the supply must equal the demand at some point. The specific point is not applicable because soil conditions are extremely variable.

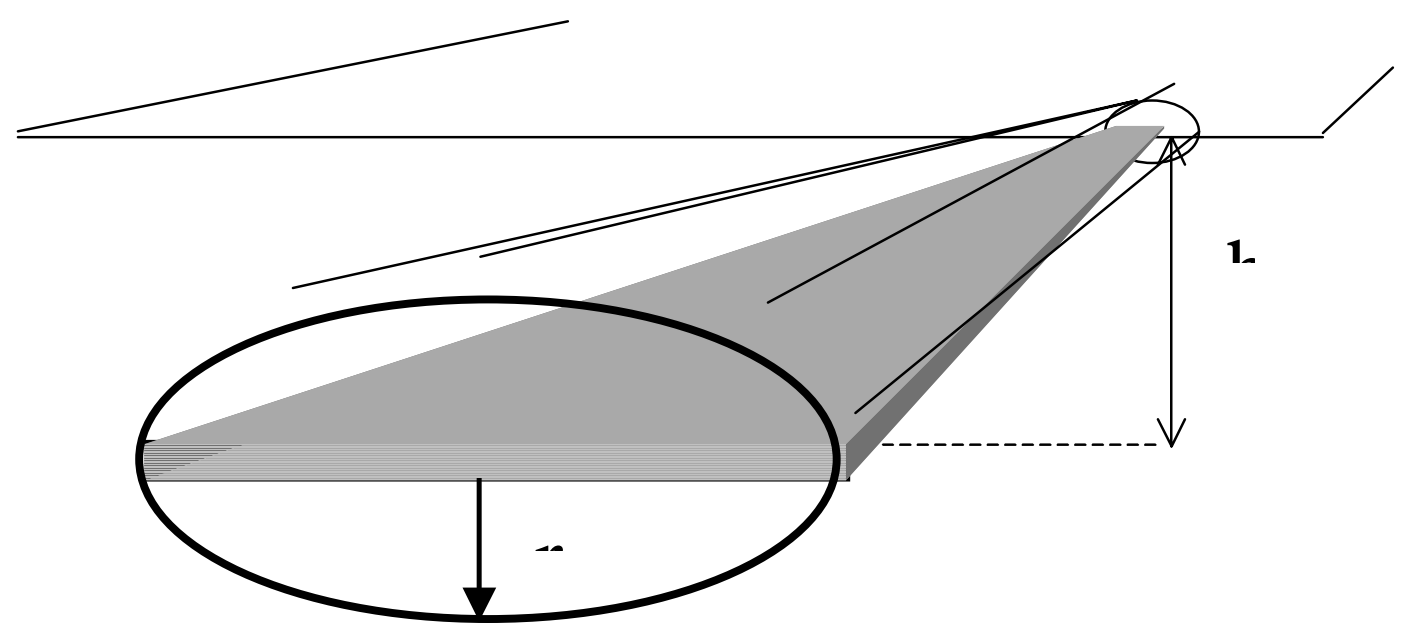

Figure 4. Schematic Representation of a Circular Trench in Accordance with a Modified Form of Fick's Law. Depth of the System is Represented by h, and $\mathrm{r}$ is the Radius of the Circular Trench.

The models presented here are based on several assumptions and have not been field confirmed. Confirmation of the input variables from laboratory physical models and field systems is needed.

\section{CONCLUSIONS}


In order to increase the oxygen flux to the infiltration surface, the system design must be long, thin, and located close to the oxygen source. A dry, porous soil loaded with a low BOD wastewater will also increase the efficiency of the system. If the oxygen supply calculated is correct, it is consistent with field observations of clogging mats.

\section{ACKNOWLEDGEMENTS}

The authors would like to acknowledge the advice and support of K-J.S. Kung, Department of Soil Science, UW-Madison.

\section{REFERENCES}

1. Carslaw, H.S. and J.C. Jaeger. 1978. Conduction of heat in solids. Clarendon Press, Oxford. p. 189-190.

2. Jaynes, D.B. and A.S. Rogowski. 1983. Applicability of Fick's Law to gas diffusion. Soil Sci. Soc. Am. J. 47: 425-430.

3. Yanful, E.K. 1993. Oxygen diffusion through soil covers on sulphidic mine tailings. J. Geotech. Engr. 119: 1207-28. 